\title{
Janitor Run: Studying the Effects of Realistic Mirror World like Game Scenes on Game Experience
}

\author{
Paula Alavesa, Olli Korhonen, Jussi Sepponen, Mikael Martinviita, Mohammed Abdrado, Minna Pakanen, Timo \\ Koskela, and Matti Pouke \\ Center for Ubiquitous Computing \\ Department of Computer Science and Engineering \\ University of Oulu, Finland \\ firstname.lastname@oulu.fi
}

\begin{abstract}
Realistic 3D models of buildings exteriors and interiors are becoming available and have a great potential to be used also as game scenes. We sought out to explore the familiarity to the game scene in relation to the game experience. For this purpose we implemented a racing game prototype set on a realistic mirror world like campus model. We deployed our game, Janitor Run, via several communications channels and had 29 answers on game experience questionnaire. Based on our results the players who visit the campus often felt less tired post-game whereas the players who visit the campus seldom had a higher positive experience and harder time returning to reality after game-play.
\end{abstract}

Keywords-Game design; Mirror worlds; Game experience.

\section{INTRODUCTION AND BACKGROUND}

Realistic 3D models are widely used to guide construction and visualizing future visions to enable citizen in city development projects [1]. The use for games is not as popular and most game scenes depicting real-life locations are often caricatures of the original such as the cityscapes in Grand Theft Auto series [2] or there is temporal displacement and alternate universe as in Fallout series [3]. In such cases, it is much easier to build the game scene according to the rules of game scene design e.g. wide and easy to navigate corridors and less intractable doors or fewer pillars to bump into [4]. Blending events or location aware contents from real life into the game scene does benefit from accurate proportions to the original. It is however debatable whether this approach is beneficial to game experience. Depicting player locations and paths in a virtual environments (VE) with realistic proportions can however be done easier just as it is done on many location based games that use map as the basis of the projected game scene [5]. Other possible benefit from using realistic VEs is being able to utilize the mental maps [6] that people have on those locations, when designing the scene contents. This would though mean that people with different levels of familiarity to the physical environment will experience the VE differently from those who do not know the site in advance. A question arises whether games using realistic VEs should then be targeted for a limited audience or do the games have potential for a wider appeal. To explore the use of realistic mirror world like 3D virtual environment as a game scene, we developed a racing game called Janitor Run (Fig. 1). Janitor Run game scene is one kilometer long center hallway of mirror world version of University of Oulu that combines campus side hallways (Fig. 1).

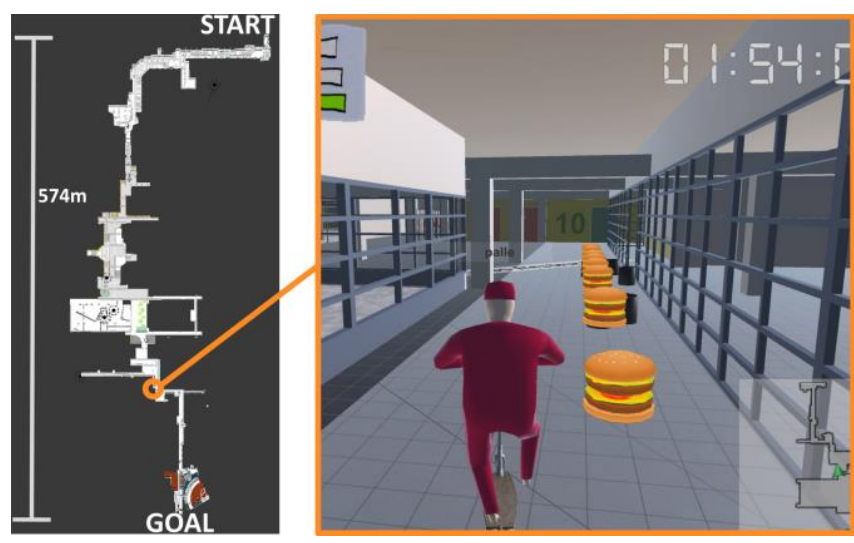

Fig. 1. The game area (left) and an actionshot from the game (right).

The university personnel frequently use kickboards for transferring along the hallways, which gave us the game topic. We adapted many of the head-up display options, minimap, player speed, leaderboard, time etc. from known racing games [7]. We added checkpoints inside the racetrack in key locations to improve the localization of the game scene, which also reflects the weather conditions on site. The game is built on top of Unity engine [8] using the free license version. The weather data is provided via Open Weather Map API [9].

\section{EXPERIMENTAL SETUP AND RESULTS}

The experimental environment for our user study was uncontrolled, restricted only by the context of playing with a PC and a keyboard. We deployed Janitor Run on various channels over two-week period: university mailing lists, social media and game development forums. We had 71 downloads and 77 individual test players. We had trouble reaching to players who are not at all familiar with the campus, albeit we did the evaluation by open deployment to reach them. We collected data via survey that ran after the players reached the goal. The questionnaire surveyed age, gender, and how familiar the players were to the university campus. In addition, it contained the game experience questionnaire (GEQ) [10]. We used the GEQ core module and the post-game module. The survey also had an open question in the end for other feedback from the players. Altogether 33 participants out of 77 players answered our survey of which we excluded two incomplete surveys and two answers in the group of people who were not familiar with our university campus at all; leaving us 29 survey responses in 
total for analysis. The answer rate was expected [11] of a voluntary survey. Of the test players, 20 were male and 9 female. Their average age was 25,5. We conducted Kruskal Wallis [12] test to analyze the results and found significant results (TABLE I. TABLE II. ) in the post-game module of GEQ that measures, positive experience (PEX), negative experience (NEX), tiredness (TIR), and return to reality (RR).

TABLE I. RESULTS FROM THE GEQ POST-GAME MODULE

\begin{tabular}{|c|c|c|c|}
\hline GEQ Item & $\begin{array}{c}\text { Visits University } \\
\text { Campus }\end{array}$ & $\mathbf{N}$ & Mean Rank \\
\hline \multirow{4}{*}{$\begin{array}{c}\text { Positive } \\
\text { Experience } \\
(P E X)\end{array}$} & Daily & 13 & 10.96 \\
\hline & Weekly & 9 & 15.50 \\
\hline & Few times a year & 7 & 17.50 \\
\hline & Total & 29 & \\
\hline \multirow{4}{*}{$\begin{array}{c}\text { Negative } \\
\text { Experience } \\
(N E X)\end{array}$} & Daily & 13 & 12.33 \\
\hline & Weekly & 9 & 16.19 \\
\hline & Few times a year & 7 & 14.36 \\
\hline & Total & 29 & \\
\hline \multirow{4}{*}{$\begin{array}{l}\text { Tiredness } \\
\quad(T I R)\end{array}$} & Daily & 13 & 10.00 \\
\hline & Weekly & 9 & 17,88 \\
\hline & Few times a year & 7 & 16.43 \\
\hline & Total & 29 & \\
\hline \multirow{4}{*}{$\begin{array}{l}\text { Return to } \\
\text { Reality } \\
(\text { RR })\end{array}$} & Daily & 13 & 10.46 \\
\hline & Weekly & 9 & 15.06 \\
\hline & Few times a year & 7 & 18.86 \\
\hline & Total & 29 & \\
\hline
\end{tabular}

The results of statistical analysis can be found in the following TABLE II.

TABLE II. SIGNIFICANCE OF GEQ POST-GAME MODULE RESULTS

\begin{tabular}{|l|l|l|l|l|}
\hline & \multicolumn{1}{|c|}{ PEX } & \multicolumn{1}{c|}{ NEX } & \multicolumn{1}{c|}{ TIR } & \multicolumn{1}{c|}{ RR } \\
\hline Kruskal-Wallis H & 3.435 & 1.164 & 6.480 & 5.516 \\
\hline df & 2 & 2 & 2 & 2 \\
\hline $\mathrm{p}$ & .179 & .559 & .039 & .063 \\
\hline
\end{tabular}

The results from the post-game GEQ are visualized in the following Fig. 2.

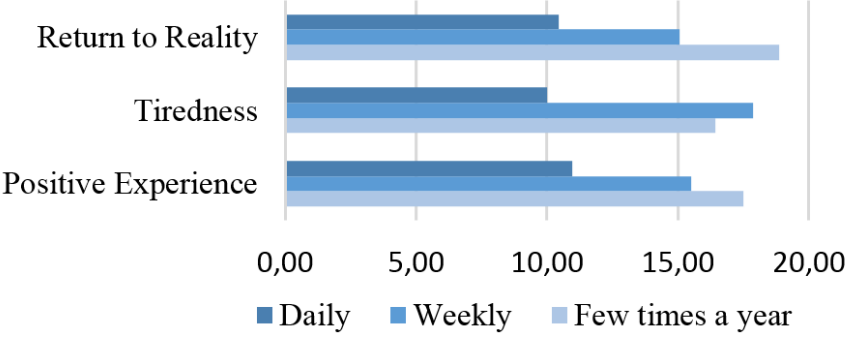

Fig. 2. Visualization of post game GEQ mean ranks of items where there was statistical significance.

Due to low number of short answers, we did not use any qualitative methods for the analysis of the answers on the open question in the questionnaire. The answers varied from nostalgic memories of the real world places, such as: "I need to go to the humanistic departments café, if it still exists." to comments on the awkwardness of racing through the realistic corridors: "Overall the controls were not similar to any of the games I played and it might take some time to get used to them. Might have been better if the map was simplified.". We further got two comments on why it was snowing indoors, although no one stated they noticed the link between to the outdoor weather at the physical campus site.

\section{CONCLUSION}

We sought to explore how the familiarity with the physical campus affects the game experience of players. The players who visit campus daily or weekly had heightened positive experience and felt less tired after the game than the other player groups. Possibly, because it was easier for them to steer their avatar through the whole racetrack, as they knew at least parts of the route, hence the cognitive load of playing the game was not very high. Alternately, the people who visit the campus more seldom found the game to be a more positive experience and had more difficulty in returning to reality after the game, which suggests higher immersion into the game environment. If the aim is to heighten immersion perhaps, the game is more suitable for people who visit the campus only on occasion. They do not know the campus enough well to break the illusion of realism of the game setting or there may even be nostalgia there to heighten their experience.

It is notable that we did not have just one group respond in a more positive way, but there was desirable effect on game experience on both people who visit the campus often and those who do not. The effect differed between used groups and was not on the same aspect of game experience.

\section{ACKNOWLEDGMENT}

This work has been supported by the Open Innovation Platforms spearhead project (A70202) and the Open City Model as Open Innovation Platform project (A71143) funded by the ERDF and the City of Oulu under the Six City Strategy program, and the COMBAT project (293389) funded by the Strategic Research Council at the Academy of Finland.

\section{REFERENCES}

[1] F. Biljecki, J. Stoter, H. Ledoux, S. Zlatanova, and A. Çöltekin, "Applications of 3D city models: State of the art review," ISPRS International Journal of Geo-Information, vol. 4, no. 4, pp. 2842-2889, 2015.

[2] Grand Theft Auto V. [DVD-CD ROM, electronical download]. Edinburgh, Scotland: Rockstar North Ltd., 2013.

[3] Fallout 4. [DVD-CD ROM, electronical download]. Rockville, Maryland, U.S.: Bethesda Game Studios, 2015.

[4] M. Nitsche, Video Game Space: Image, Play, and Structure in 3D Game Worlds. Cambridge: MIT Press, 2008.

[5] Pokemon Go. [iOS, Android] Niantic. 2016.

[6] K. Mania, A. Robinson, and K. R. Brandt, "The effect of memory schemas on object recognition in virtual environments," Presence: Teleoperators and Virtual Environments, vol. 14, no. 5, pp. 606-615, 2005.

[7] Trackmania. [Electronical download] Nadeo, Paris, France. 2016.

[8] Unity. [cross platform]. San Francisco, California, U.S: Unity Technologies, 2005.

[9] "Current weather data- OpenWeatherMap." [Online]. Available: https://openweathermap.org/current. [Accessed: 28-Apr-2017].

[10] W. IJsselsteijn, K. Poels, and Y. A. W. de Kort, "The game experience questionnaire," Manuscript in preparation, 2008.

[11] K. B. Sheehan, "E-mail survey response rates: A review," Journal of Computer-Mediated Communication, vol. 6, no. 2, pp. 0-0, 2001.

[12] P. E. McKight and J. Najab, "Kruskal-Wallis Test," Corsini Encyclopedia of Psychology, 2010. 